\title{
MYOCARDIAL TOXOPLASMOSIS
}

\author{
BY
}

\author{
J. W. Paulley, RONAld JONES, W. P. D. GREen, AND E. P. KANE
}

From the East Suffolk and Ipswich Hospital

Received June 25, 1955

In an earlier article we reported (Paulley et al., 1954) a series of cases with myocarditis believed to have been caused by toxoplasma infection. In this paper the cases previously described are again presented with the addition of photographs, photomicrographs, and electrocardiographic tracings. More details of the necropsies are included, and there are more data concerning other members of the patients' families. A further case probably of the same nature is recorded.

Pseudocysts of toxoplasmosis have been observed several times in the heart muscle of patients dying of the acute generalized acquired variety of the disease (Pinkerton and Weinman, 1940; Pinkerton and Henderson, 1941; Nery Guimarães, 1943; Kass et al., 1952; Sexton et al. (quoted by Kass, 1952); and Prior et al., 1953). In most cases evidence of the infection has also been found in the brain, spleen, liver, and lungs. In the hearts of these acute cases focal necrosis is the common finding. Electrocardiography was carried out in two instances before death. Bengtsson (1950) appears to have been the first to report myocarditis as a presenting feature of toxoplasmosis, although here again it was part of the usual clinical picture of the acute acquired disease. It provided a further example of the liability of laboratory workers to this infection, and on this occasion the oral route was the probable avenue of infection. After a long convalescence recovery took place.

Our observation occurred in the following way. A young man presented in 1954 with an unexplained severe myocarditis, and some signs suggestive of meningo-encephalitis. Eventually a speculative diagnosis of toxoplasmosis was advanced and the serum was examined through the courtesy of Dr. Cathie. The complement fixation test was strongly positive. It was realized that this might be a chance finding, until a fortnight later another patient of 39 with unexplained myocarditis was also found to have a positive test. A thorough investigation was then made of these two patients' families, with startling results not only in the number of positive complement fixation tests, but also in the findings of quite unsuspected symptomless heart disease in young siblings, and in one of the families a striking tale of sudden death or heart failure in a mother of 39 , a brother of 16 , and a sister of 20 . A third patient, aged 24 , was then found, symptom free, who had been medically rejected for Sandhurst because of a large heart at the age of 19; he, too, had strongly positive serological tests.

Positive complement fixation tests may be expected in 5 per cent of the population in NorthWest England (Macdonald, 1950) and in Cathie and Dudgeon's series (1953) the figure is given as 7 per cent. The frequency of positive tests in our cases and their close relatives provided most powerful circumstantial evidence that in fact toxoplasmosis was the cause of the myocarditis.

Ultimate and absolute proof was, however, lacking. We had been unable to find pseudocysts in the only heart of our series available for microscopic examination. An attempt to grow toxoplasmas by mouse inoculation with a suspension of finely ground heart muscle from one of our patients, who died a few months ago, failed. But very recently Cathie has reported (1955) successful isolation of toxoplasmas by mouse inoculation from the heart muscle of a patient of Dr. Alun 
Williams of Middlesborough who died of an obscure myocarditis and in whom the serological tes had been found positive six weeks previously (C.F.T. 1/8; dye test 1/32). This was most importa! confirmatory evidence for our thesis which had previously relied on serological tests and a certai. degree of probability.

\section{Case Reports}

Case 1. A man, aged 24, was admitted to the East Suffolk and Ipswich Hospital on Sept. 20, 1953. He had a large left pleural effusion, low grade fever, a large heart (Fig. 1), and residual signs of a stroke affecting the right side which had occurred a week before he came in. He was treated with penicillin and streptomycin and was discharged a month later, only to be readmitted on February 19, 1954, with cardiac failure. Electrocardiograms showed auricular fibrillation and severe left bundle-branch block (Fig. 3). There was fever and mental confusion and left hemiplegia. He was reviewed at a clinical meeting, and among others the diagnosis of toxoplasmosis was $c_{\text {unidered. }}$

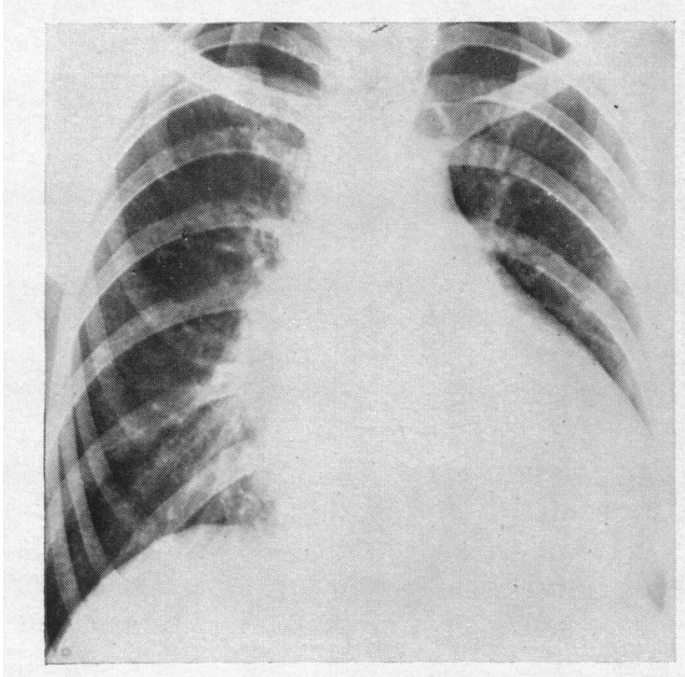

FIG. 1.-Case 1. Teleradiogram of heart, January, 1954.

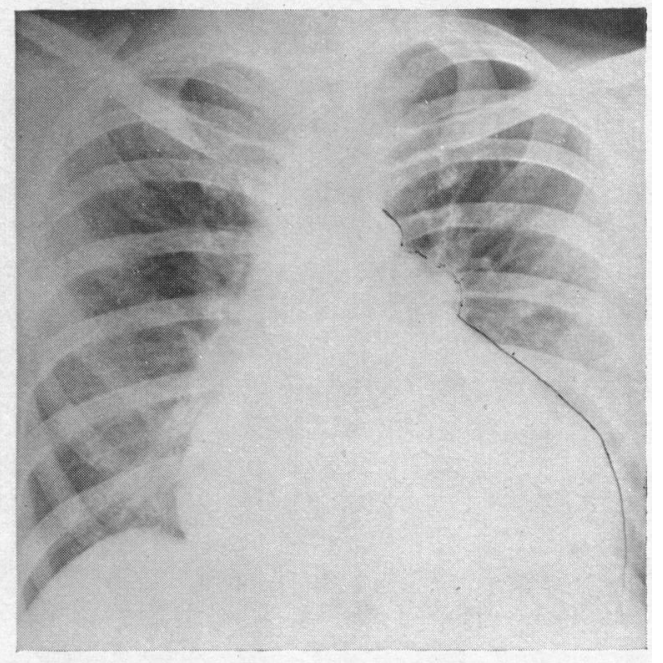

FIG. 2.-Case 2. Teleradiogram of heart, May, 1954.

Dr. I. A. B. Cathie tested the patient's serum for toxoplasmosis and found that the dye test was positive at $1 / 64$, and the complement fixation test at $1 / 16$. The patient's skull was radiographed, but no cerebral calcification was found. Efforts were then made to obtain further details of his family history. The patient's condition deteriorated gradually, and he died on Dec. 10, 1954.

Necropsy Report. Scalp, skull, and meninges were normal. The arteries at the base of the brain showed no evidence of disease. In the right cerebral hemisphere there was extensive old cystic softening of the lenticular nucleus, yellowish in colour and largely replaced by clear fluid. Its appearances were consistent with a duration of about one year. The remainder of the brain showed no naked-eye change and in particular there was no evidence of any calcification.

The heart weighed 960 grammes. The coronary arteries were of medium calibre and showed no evidence of atheroma. The myocardium everywhere showed extensive yellowish mottling or fibrosis. This was most marked at the apex where the consistence of the muscle was exceedingly dense and where there was a small amount of intramural thrombus formation. There was no evidence of any intra-auricular thrombus formation. The valves were normal (Fig. 4).

The liver weighed 1650 grammes. Its cut surface showed an appearance of very advanced nutmeg change.

Histological Examination. Sections of five portions of heart from different areas all showed substantially the same changes (Fig. 6 and 7). 


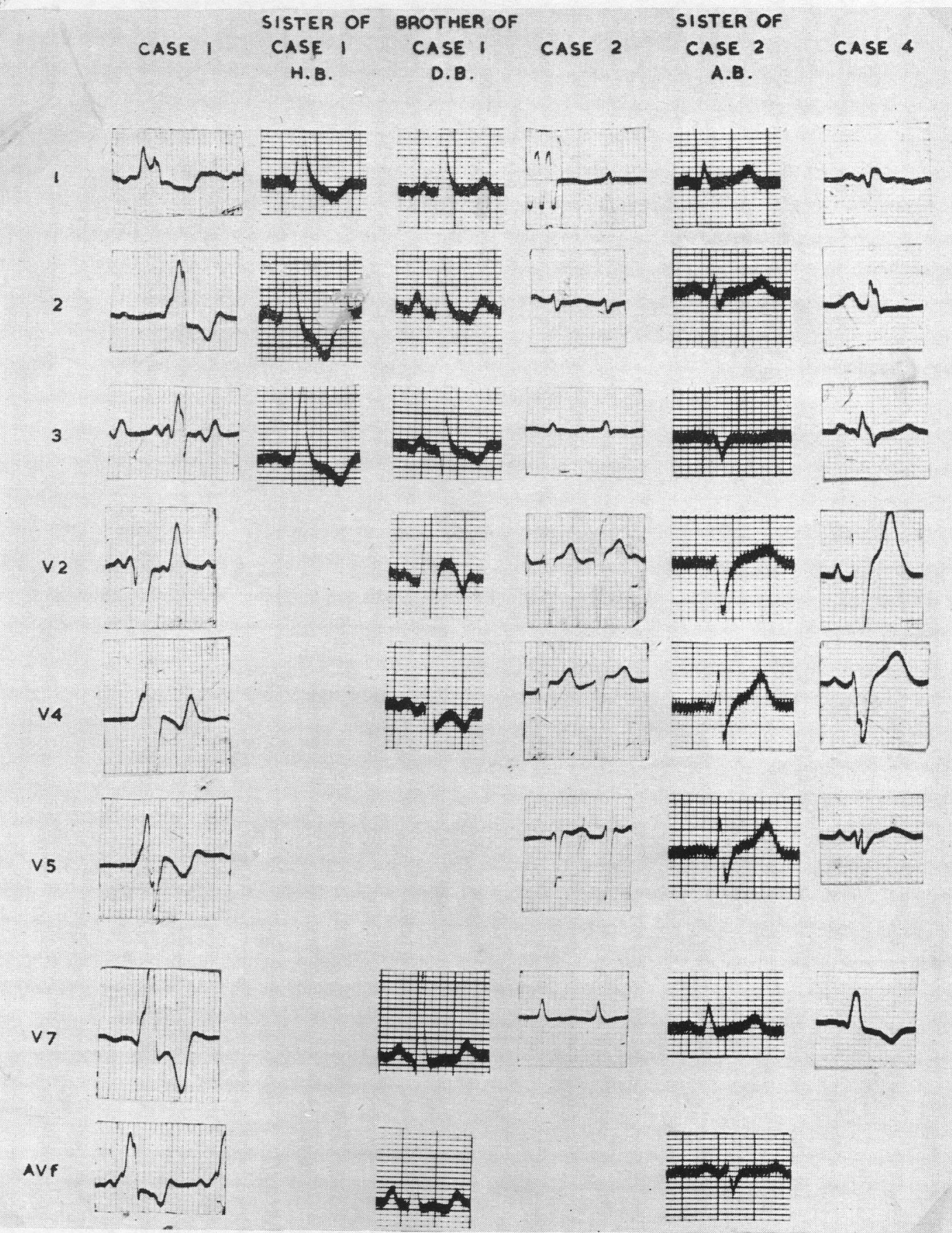

FIG. 3.-A series of electrocardiograms from Cases 1, 2, and 4, and some of their relatives. 


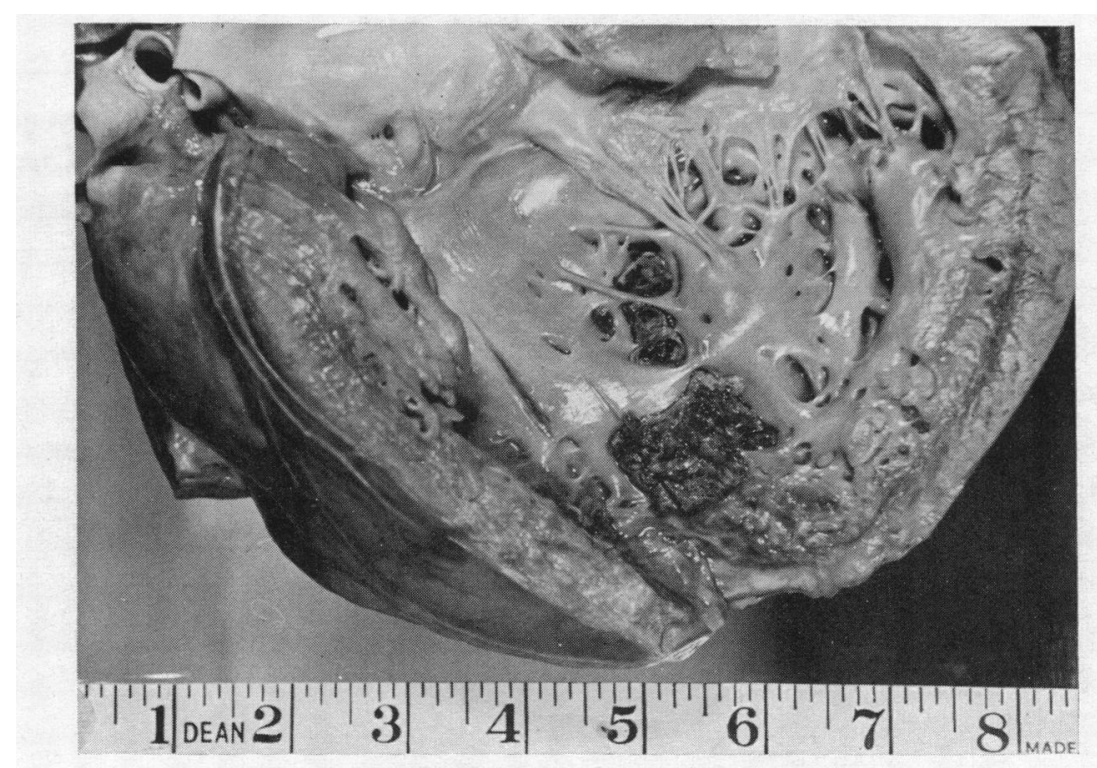

FIG. 4.-The heart of Case 1, showing hypertrophied muscle, fibrosis, and intraventricular thrombus. Scale in inches.

1. Hypertrophied irregular muscle fibres (this change was less marked in areas with less fibrosis).

2. Generalized fine interstitial fibrosis varying from slight to moderate in degree.

3. Extensive areas of coarse fibrosis surrounding isolated hypertrophied myocardial fibres and often surrounding or adjoining tracts of necrotic-looking fibres.

4. No significant degree of active inflammatory cell infiltration and no evidence of pseudocysts or other indication of active toxoplasmosis.

Sections of pons and medulla showed no abnormality. The area of softening in the lenticular nucleus showed no specific changes and in particular appearances rather suggestive of miliary granulomata or pseudocysts were seen in the adjoining brain tissue.

Family History. The patient's mother died suddenly at the age of 39 in 1944 . At necropsy the body was that of a well nourished woman. The legs were œdematous and the abdomen prominent. The brain showed an embolic necrosis in the left parietal lobe. The air passages contained frothy sputum. The lungs were large, firm, and slightly œdematous. The heart was very large (550 g.). All cavities were hypertrophied and dilated. The valves were normal and the coronary arteries healthy. There was ante-mortem clot in the left auricular appendage. The left ventricle was fibrotic. The liver was large and showed extensive chronic venous congestion. The spleen was firm and showed approximately three-fold enlargement. The kidneys were normal. The pelvic organs and intestines were normal. Death was due to congestive heart failure, myocardial fibrosis, and hypertension. Histological appearances were not recorded.

The father, upset by the mother's death and the responsibilities of his family, went into a mental hospital in 1945 and is still there. His heart is clinically normal. The complement-fixation test was anticomplementary, but the dye test was positive at 1/4. A brother of the patient died suddenly at the age of 16 in 1947 in a children's home. He is said to have had "meningitis" at the age of 3 years and to have had epileptic fits afterwards. A coroner's inquest and necropsy attributed death to heart failure from paroxysmal tachycardia, from which he is said to have suffered. His heart was generally enlarged at necropsy, and he had a large "fibrotic spleen." A second brother, aged 20, spends half his time in an institution and the other half "on the road." Since our first paper he has been traced and examined. There is no clinical evidence of heart disease, and his serological reactions and cardiogram and teleradiogram are all normal. A sister (twin of the second brother) died suddenly in June, 1954, in Whittington Hospital a few days after childbirth. She was admitted there in May, 1954, six months pregnant, and cardiac arrhythmia had been noted in the antenatal clinic. Edema and albuminuria then developed, and she was thought to have 
pregnancy toxæmia. The diagnosis was soon changed to congestive heart failure. There were no heart murmurs but many ectopic beats. Electrocardiography showed gross myocardial changes culminating in bundle-branch block (Fig. 3). She deteriorated despite treatment, and died with an embolism of the bifurcation of the aorta. At necropsy "myocarditis of unusual type" was found, the embolus arising from intracardiac thrombosis of the left auricle and ventricle (Fig. 5). Dr. J. D. O'D. Lavertine reported on the myocardium: "Severe cloudy swelling of hypertrophied fibres, slight fatty change, areas of dense young fibrous tissue, and diffuse fibrosis with focal non-specific chronic inflammation in myocardium of both ventricles, and with endocardial thrombosis. ... The condition appears to be a non-specific myocarditis in the healing phase following severe focal necrosis." (Fig. 8). A third brother, aged 18, is in the army and

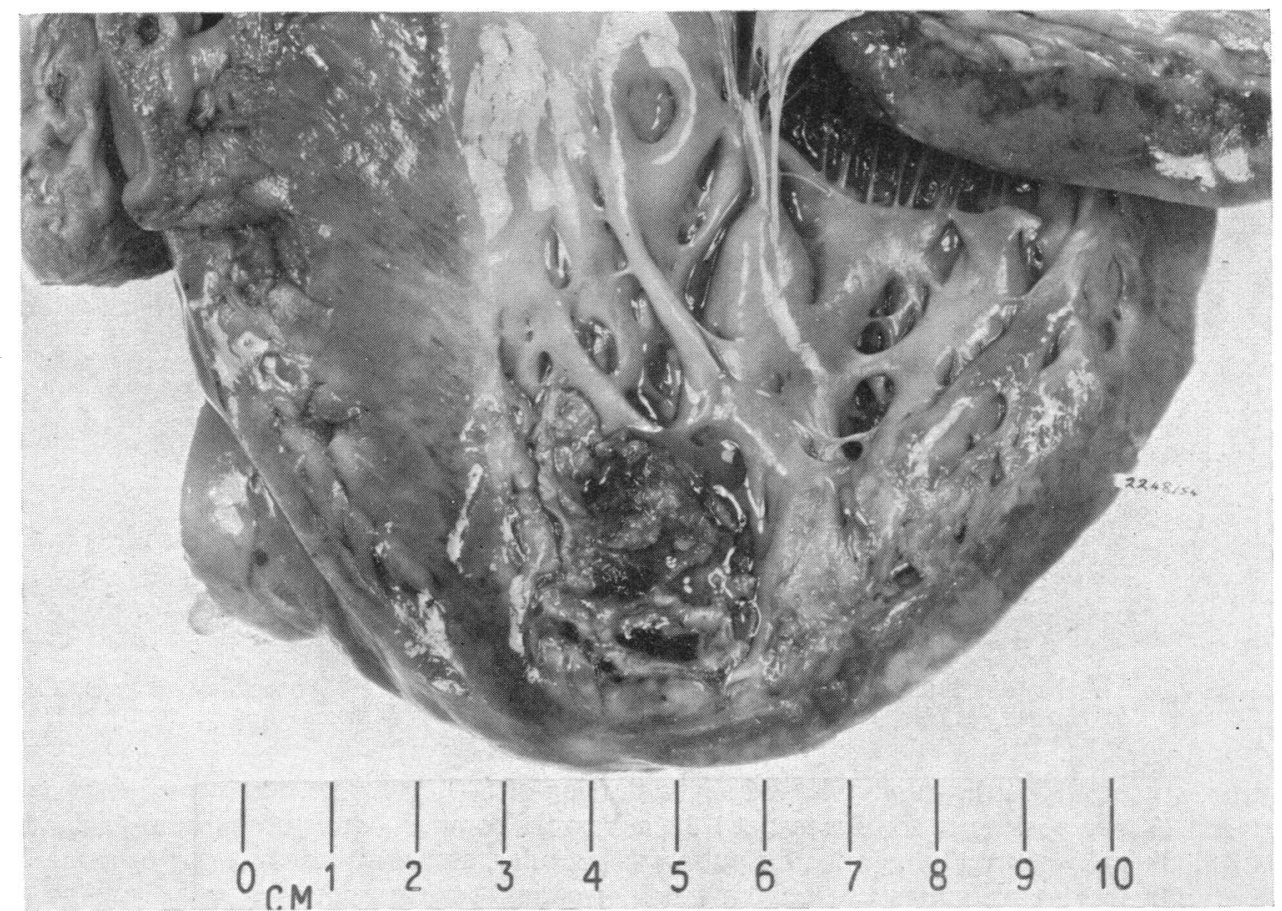

FIG. 5.-The heart of the sister of Case 1 (June S), shown for comparison.

doing well. He went to an approved school, and was not available for examination. A second sister, aged 15 , has been in a children's home for ten years. Her I.Q. is 75 and electrocardiogram very abnormal, with wide QRS $(0.12 \mathrm{sec})$. Radiographs of her chest and skull were normal. Her serum gave a positive result with the complement-fixation test at $1 / 16$, and dye test at $1 / 32$. A fourth brother, aged 13, has been in a children's home ten years. His I.Q. is 71, and electrocardiogram showed a prominent Q3, a small $R$ wave in V1, a diphasic $\mathrm{T}$ in V1 and inverted $\mathrm{T}$ in V2 and V3, and slurring of S-T in V1-4. Radiologically his heart is of normal size. His serological findings have been negative.

Case 2. A man, aged 39, was admitted to hospital with dyspnœa on slight exertion and ankle œdema. Breathlessness had been gradually increasing for eight years. He had pain in his chest on hurrying. At the age of 17 he had had a "serious illness" described as jaundice and "gastric flu."

Examination revealed auricular fibrillation, a very large heart (Fig. 2), and a systolic murmur at the apex. Cardiogram showed complexes of very low voltage (Fig. 3). Because of our experience with Case 1 tests for toxoplasmosis were done, the dye test being positive at $1 / 32$ and the complement-fixation test at $1 / 16$.

The family history showed that his father was alive and well and that his mother died of cancer. A sister aged 37, was positive to the dye test at $1 / 16$ and to the complement fixation test at $1 / 16$. Another sister, aged 29, was negative to the dye test and the complement-fixation test. Radiography of her skull and chest 


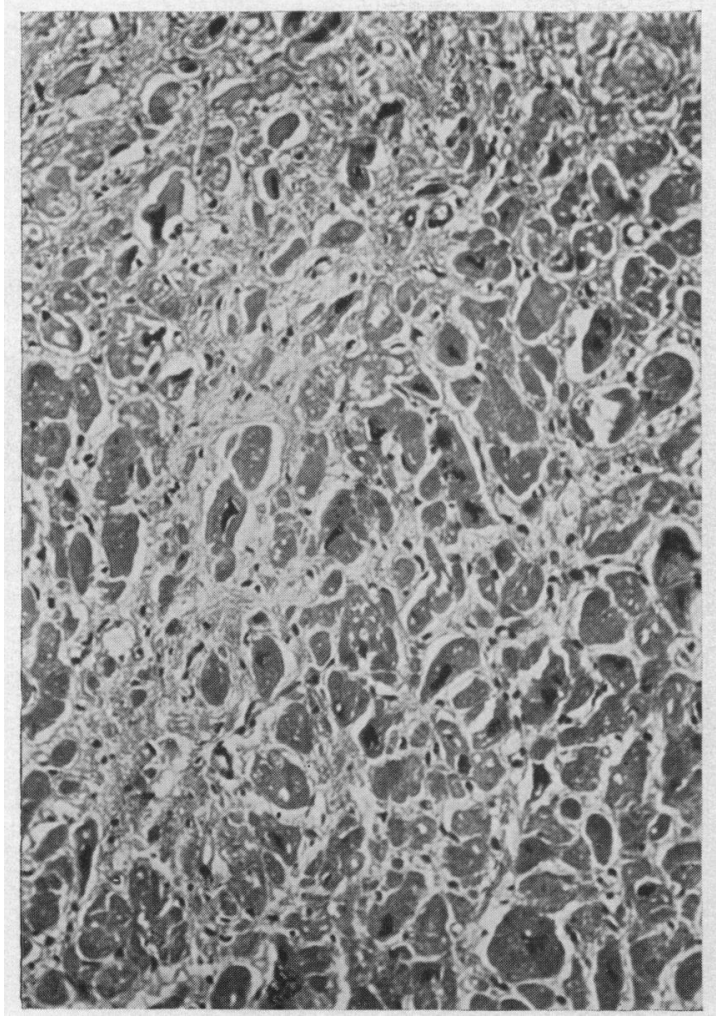

FIG. 6.-Case 1. Myocardium, showing diffuse fibrosis $(\times 74)$.

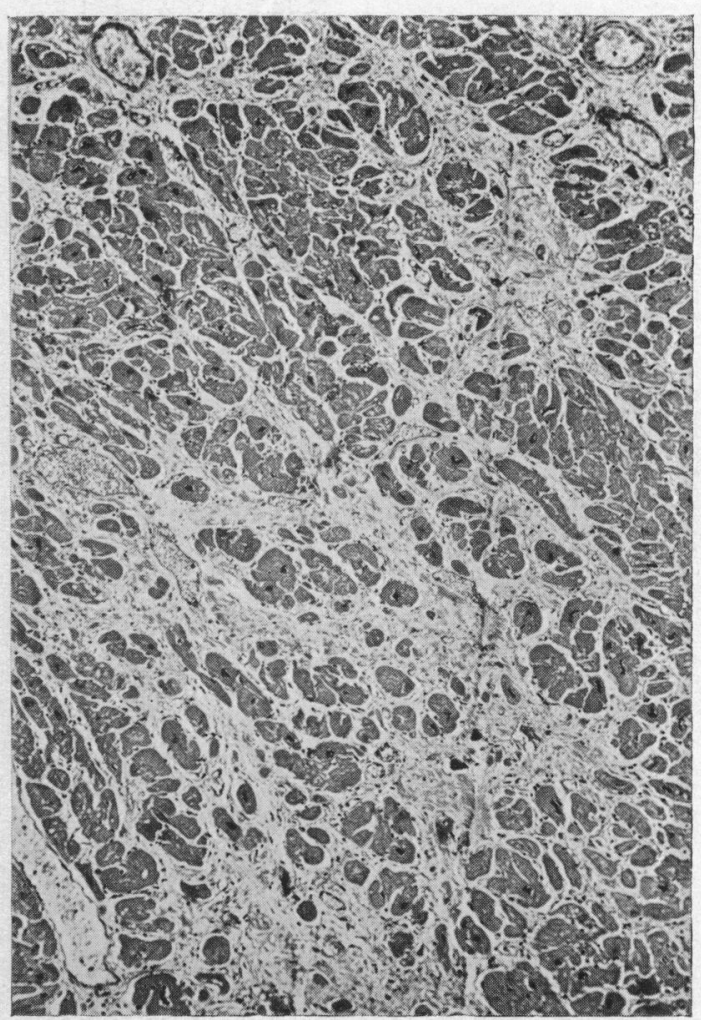

FIG. 7.-Case 1. Myocardium, showing diffuse fibrosis $(\times 190)$.

was normal, and electrocardiography showed slight slurring of S-T segments. She was symptomless. A brother, aged 23, was positive to the dye test at $1 / 32$, and to the complement-fixation test at $1 / 32$. His heart was enlarged clinically and radiologically, his pulse was irregular, and electrocardiography showed auricular fibrillation. He was symptomless apart from much sweating on exertion. He had "german measles" twice, at the age of 11 and 19 years. Pets were always kept in this household, at one time as many as nine cats.

Case 3. A man, aged 24, was seen as an outpatient in June, 1954. He had no symptoms and played strenuous games, but had been rejected by a Service Medical Board at the age of 19 because of cardiomegaly, and a life assurance company had referred him for an opinion on his heart. He himself had had no serious illness.

On examination his heart was much enlarged. No heart murmurs were heard. Electrocardiographic findings were regarded as within normal limits. Because of our experience with the first two cases, serological tests for toxoplasmosis have been done, with the following results: dye test positive at $1 / 512$ complement-fixation test positive at $1 / 32$.

Case 4. An engineer's labourer, aged 43, complained in May, 1954, of a cough and frothy sputum waking him at night. He was diagnosed by his own doctor as having influenza, but he did not recover fully. In July, while on holiday, he noticed breathlessness on going up steps or when hurrying on the flat. In August he tried to return to work but had to give up after a week. He was admitted to hospital in December, 1954, for investigation. There was a history of pneumonia in 1943 and sciatica in 1952 . He had otherwise been well and there was no history of recurrent winter cough. He had never had rheumatism.

Examination showed a small thin man, slightly cyanosed. A malar flush was present. There was no œdema. The pulse was 68 a minute and regular, the blood pressure 80/70. Gallop rhythm was present, but there were no murmurs. Fine râles were found at the lung bases. The liver was enlarged two finger- 
breadths. He was regarded at once as "a very obscure case." The cardiogram showed right bundle-branch block, but no evidence of recent infarction (Fig. 3); after a test exercise there was no alteration in complexes to suggest ischæmia. Blood was then sent for toxoplasmosis tests; the C.F.T. was positive at $1 / 8$ and dye test positive at $1 / 32$. At the same time he was readmitted as an emergency with what turned out to be a thrombosis at the bifurcation of the aorta. He developed rapid auricular fibrillation terminally.

Necropsy Report. The heart weighed 520 grammes. The coronary arteries showed fairly extensive atheroma but were of wide calibre with no evidence of obstruction. Both ventricles were dilated; there was no pronounced thickening of their walls. The myocardium was very firm and of dense consistence; it showed generally a mottled appearance of coarse fibrosis; there was no evidence of any recent infarction. The valves were normal. There was no auricular thrombus formation.

The lower abdominal aorta showed fairly advanced atheroma. There was a large adherent thrombus completely occluding the lower $3 \mathrm{~cm}$. and extending into the first few $\mathrm{cm}$. of both common iliac arteries.

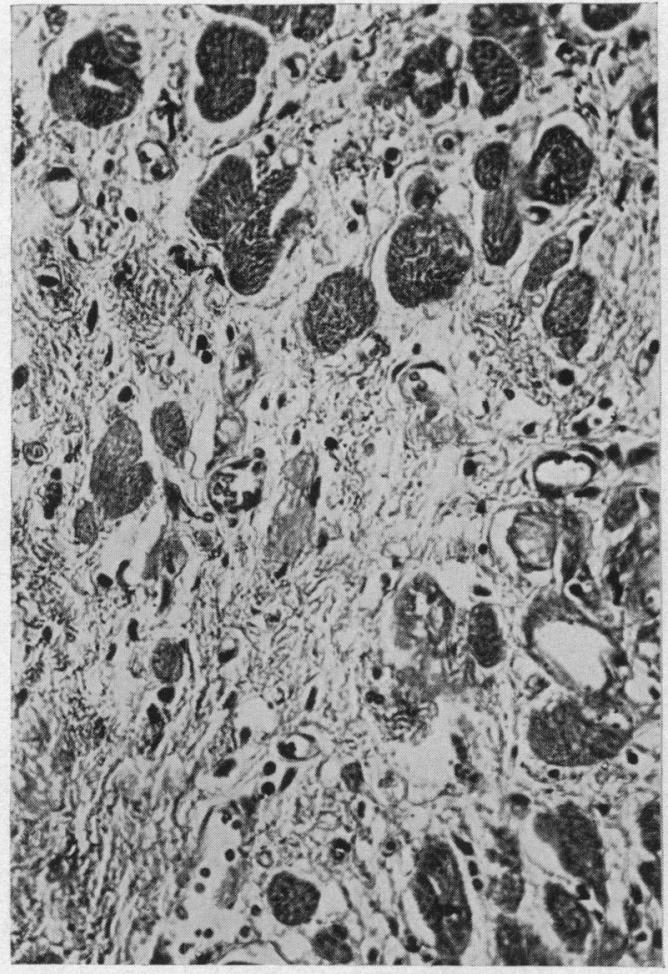

FIG. 8.-June S. Myocardium, showing necrotic muscle fibres $(\times 310)$.

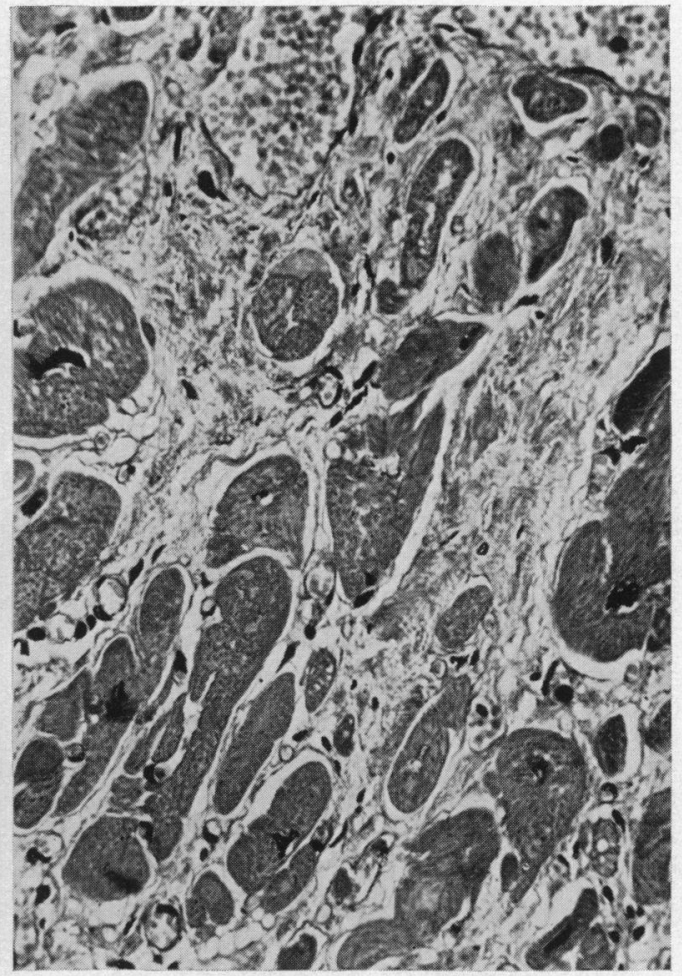

FIG. 9.-Case 4. Myocardium, showing fibrosis and hypertrophied muscle fibres $(\times 310)$.

Histological examination of five pieces of the heart all showed extensive interstitial fibrosis. This was predominantly of loose acellular type. The distribution was fairly widespread although there were areas unaffected. The muscle fibres showed much hypertrophy. In the more severe areas of fibrosis they appeared degenerate-swollen and eosinophilic with loss of striation. No active inflammatory cell infiltration was seen and the process was obviously of long duration. Nothing was seen to suggest the presence of toxoplasma (Fig. 9).

Family History. After his death efforts were made to obtain details of his family history. His father died, aged 39. His mother had been ill with heart failure for a year before death at the age of 36 of dropsy. He was the youngest of four children. The eldest sister was interviewed and she said that she and the other brother and sister were well as far as she knew. Her blood was taken for toxoplasmosis tests and was 
negative. The patient's wife and two children aged 7 and 9 also have normal findings in the serum. Teleradiograms of the chest and electrocardiograms were also carried out on the patient's family; they were considered to be within normal limits though there was slight doubt about the children's cardiograms and we intend to follow them futher.

\section{DisCUSSION}

Since our previous communication more data have presented. The serological examination of June S's baby gave negative results; this was of interest as we expected them to be positive. However, there is no proof that the mother's blood was positive, though we believe it should have been. Also her twin brother returned from his wanderings, and in him full clinical examination, heart radiography, cardiography, and serum were normal. These findings are in the main against the infection in our cases being congenital, and this we had suspected previously because of the skipped sibling in the family of Case 2, and because of the 16 years separating Case 2 and his diseased younger brother. Necropsy of Case 1 revealed a heart almost identical macroscopically as well as microscopically with his sister's. Examination of the brain showed no evidence of encephalitis, but an area of softening of the right lenticulate nucleus was considered to be due to an old infarct.

Case 4 is of interest, as although his heart was large during life, at necropsy it did not show the gross hypertrophy of Case 1 or June S. This patient, rather older than the previous cases, was thought to have suffered a silent cardiac infarction and his bundle-branch block had been attributed to coronary disease until the positive serological test and necropsy. It is tempting to think that this is a common occurrence where unexplained heart failure is often attributed to previous hypertension, burnt out thyrotoxicosis, or coronary vascular degeneration with little evidence to support these diagnoses.

The consistent finding of cases in which the heart seems to be the organ predominantly affected could be explained by a specific strain of the organism with special affinity for heart muscle. Such a concept is perhaps not too extreme if one considers as parallels, leishmaniasis and trypanosomiasis, diseases caused by organisms comparable to toxoplasma, and displaying a variety of clinical features according to strain. A study of South American trypanosomiasis is particularly interesting in this respect, the organism having an undoubted predilection for heart muscle as well as brain and liver. Histologically, too, the appearances of the pseudocysts in Chaga's disease are somewhat similar to those of toxoplasma.

The questions of latency and chronicity remain undetermined. The fact that so many members of the families of Cases 1 and 2 are affected despite their ages being widely separated suggests latency though it is by no means proof of it. As is thought to happen in Chaga's disease there may be initial heart damage, and the subsequent healing may be partial or complete. If partial, the eventual heart failure is likely to be delayed many years. However, the presence of much necrosis of muscle fibres in the hearts of Case 1 and his sister June $S$. suggested recent activity, though we had every reason to suspect that their hearts had been infected many years before, because of the death of their mother in 1943 and a brother in 1947 apparently from the same condition.

The whole question of the serological tests and what they mean has been reopened by the recent Sheffield report (Beverley et al., 1955) of a laboratory worker whose complement fixation test became negative within a few months of infection (Beattie, 1955): hitherto it had been thought that this did not happen. High, or rising titres in the dye test are essential for much reliance to be placed upon it, especially as it has now been shown that low titres can be caused by trichomonas vaginalis infection. In our own series, D.B., the younger brother of Case 1, had an electrocardiogram showing some evidence of anterior myocardial damage, but serological tests had been twice negative: clinically, however, he showed no sign of heart disease and his heart was of normal size. It is difficult to interpret this finding and to assess how much weight should be attached to it. At first sight the cardiograms of the children of Case 4 appeared abnormal, but 
measurement and allowance for age has shown them to fall within physiological limits. We hope to follow the future of these three children, as there is an element of doubt.

It seems most important that every effort be made to isolate the toxoplasmas from heart muscle more frequently by mouse inoculation as Siim has done so successfully from lymph glands.

A possibility that has to be considered is that the toxoplasma infection in these myocarditis cases is incidental, and not primarily the cause of the heart damage. This presupposes that some situation had arisen in these patients which had encouraged a flare up of an earlier infection lying latent, or that they have become more liable to infection because of lowered resistance. We do not think that either of these theories is the probable explanation.

Despite the present uncertain position we suggest that toxoplasmosis should be suspected in all forms of obscure myocarditis, especially in familial cardiomegaly and idiopathic cardiac hypertrophy, and perhaps in some cases at present described as coronary disease in the young. Many of the histological changes in our cases could have been caused by long standing ischæmia, and though we found the large coronary vessels singularly free of disease in our patients, we have no evidence as to the state of the smaller branches.

\section{SUMMARY}

Focal myocarditis due to toxoplasmosis has been recorded several times as part of the generalized acquired disease. Evidence is advanced that myocarditis may be the only presenting sequela of an earlier infection with toxoplasma, or a manifestation of an infection lying latent for a long time.

Details of four cases are recorded and of many members of their families who, though symptomless in the main, showed evidence of unsuspected heart disease on X-ray and electrocardiographic examinations.

A brother of Case 1 had an abnormal electrocardiogram but negative serology. The importance of this finding is discussed, especially in the light of the recent Sheffield patient in whom the complement fixation tests became negative within months of a known acquired toxoplasma infection.

A suggestion is made that there may be some similarity between myocardial toxoplasmosis and Chaga's disease.

Toxoplasmosis should be excluded in all forms of obscure myocarditis and especially in familial cardiomegaly and idiopathic hypertrophy. In the event of death every effort should be made to isolate the organism by mouse inoculation of the finely ground myocardium.

\section{ADDENDUM}

A fifth case, a working farmer, aged thirty-four has recently presented. Cardiomegaly was found during examination before emigration. He was symptomless, apart from palpitation since the age of 15, for which he was investigated in 1940 with no clinical or cardiographic abnormality except tachycardia. Now there is general cardiomegaly and cardiograms show left ventricular stress. Toxoplasmosis dye test positive 1/16; complement fixation test positive 1/8. Thyroid activity normal. The rest of his family are being investigated.

We are most grateful to Dr. I. A. B. Cathie for the serological investigations and to Dr. A. L. Jacobs and J. D. O'D. Lavertine for details of the sister of Case 1 and for the photograph of her heart. We are also much indebted to Dr. N. R. Barrat of Cambridge for arranging for the photomicrographs to be done in his department.

\section{REFERENCES}

Beattie, C. P. (1955). Proc. Roy. Soc. Med. In the press.

Ball, J. D., Williams, A. W., and Davies, J. N. P. (1954). Lancet, 1, 1049.

Bedford, D. E., and Konstam, G. L. S. (1946). Brit. Heart J., 8, 236.

Bengtsson, E. (1950). Cardiologia, 17, 289.

Beverley, J. K. A., Skipper, E., and Marshall, S. C. (1955). Brit. med. J., 1, 577.

Campbell, A. M. G. (1953). Proc. Roy. Soc. Med., 46, 891.

Cathie, I. A. B., and Dudgeon, J. A. (1953). Great Ormond St. J., 5, 13 
Davies, L. G. (1952). Brit. Heart J., 14, 206.

Evans, W. (1949). Brit. Heart J., 11, 68.

Fiedler, A. (1889). Ueber akute interstitielle Myokarditis. Festschrift zur Feier des 50 jahr. Bestehens des Stadtkrankenhauses zu Dresden-Friedrickstadt Dresden, part 2, 3.

Gillanders, A. D. (1951). Brit. Heart J., 13, 177.

Gilmore, H. R. jun., Kean, B. H., and Posey, F. M. (1942). Amer. J. trop. Med., $22,121$.

Hart, E. W., Paulley, J. W., Rivers, J. S., and Westlake, E. K. (1951). Arch. Middx. Hosp., 1, 26.

Higginson, J., Gillanders, A. D., and Murray, J. F. (1952). Brit. Heart J., 14, 213.

Kass, E. H., Andrus, S. B., Adams, R. D., Turner, F. C., and Feldman, H. A. (1952). Arch. intern. Med., 89, 759.

Macdonald, A. (1950). Lancet, 2, 560.

Nery Guimarães, F. (1943). Mem. Inst. Oswaldo Cruz, 38, 257.

Paulley, J. W., Jones, R., Green, W. P. D., and Kane, E. P. (1954). Lancet, 2, 624.

Pinkerton, H., and Henderson, R. G. (1941). J. Amer. med. Ass., 116, 807. and Weinman, D. (1940). Arch. Path., 30, 374.

Prior, J. A., Cole, C. R., Docton, F. L., Saslaw, S., and Chamberlain, D. M. (1953). Arch. intern. Med., $92,314$.

Sabin, A. B., Eichenwald, H., Feldman, H. A., and Jacobs, L. (1952). Arch. intern. Med., 150, 1063.

Sexton, R., Eyles, D. E., and Dillman, R. E. Personal Communication quoted by Kass et al.

Siim, J. C. (1955). Proc. Roy. Soc. Med., In the press.

Strom, J. (1951). Acta med. scand., 139, 244.

Vulliamy, D. G. (1947). Brit. Heart J., 9, 161. 